\title{
The Application of Hybrid Library Concept in Collaboration and Circulation Area of the University Library
}

\author{
Monica Libertyna Lukman ${ }^{1 *}$ Noeratri Andanwerti ${ }^{1}$ Silvia Meliana ${ }^{2}$
}

\author{
${ }^{1}$ Interior Design Department, Faculty of Art and Design, Tarumanagara University, Jakarta 11440, Indonesia \\ ${ }^{2}$ Interior Design Department, School of Design, Bina Nusantara University, Jakarta 11480, Indonesia \\ *Corresponding author. Email: monica.615170097@stu.untar.ac.id
}

\begin{abstract}
The digital generation makes science and technology improve significantly, including libraries that are used as an educational space for students. The hybrid library concept is a continuation of conventional libraries that utilize digital technologies in the system. The idea can meet the digital generation's needs as a sociable generation that relies on technology daily. Tarumanagara University Library applies the hybrid concept as the design theme and contemporary style. The purpose of this paper is to ascertain that the hybrid concept can solve the library's problems. The design process uses programmatic methods by analyzing the data, creating the design concept, and then realizing it in a 3D perspective. Meanwhile, this paper uses a qualitative approach with descriptive explanations. This paper's final result is a library that applies technological developments in its system and collaboration spaces for its users.
\end{abstract}

\section{Keywords: Circulation area, collaboration area, digital generations, hybrid library, interior design}

\section{INTRODUCTION}

Globalization has become a phenomenon for the world community [1]. Currently, Indonesia has entered the era of globalization, which can be seen from society's practical and digital life, especially people in urban areas. Digitalization is the keyword in this era, be it digitizing communications, digitizing products and services, digitizing business, and digitizing information [1]. There are many ways to obtain this information, one of them is through the library. The library is a forum for people of all ages to gain knowledge [2]. Libraries also play an essential role in improving human resources quality in this globalization era [2]. One of the library types that significantly impact the digital generation's education is a University Library. Students as a digital generation have a significant influence on the future of human resources because they are the ones that will lead the changing of an era in the future[3].

The Digital Generation (Gen Z) are the natives of the digital era, and they were born after 1995 when the digital age has developed rapidly. They are good at socializing but also have an individualistic nature. Social media and technology have become a part of their lives. They are a generation that is well organized [4], self-directed, instant-cultured, and educationally transformed, according to Tuhana. $\mathrm{T}$. Andrianto [5] in Kompasiana News [6], It is predicted that there will be a "Generation Z" boom around 2020, where activities rely heavily on digital formatted gadgets. This is what encourages libraries to evolve according to the needs of its users, a library that can provide facilities and access to the right information and the right users practically and quickly, by utilizing technologies in the system and its management. According to F.W.Lancaster [7] retrieved from Anna Nurhayati journal [8], a librarian and a lecturer in the field of library science in America predicts that the impact of the growth of technology information and communication will change the society, this period is called the paperless society, and there will be a network based on a communication system that has many characteristics, that is currently known as an internet-based technology.

However, this change cannot just happen right away. Many things must be considered to transform a conventional library into a digital library. Thus, a concept was created, which is the intermediate of traditional libraries and digital libraries, that is, hybrid libraries [8]. Oppenheim and Smithson [9] say that a hybrid library is a half step towards a fully digital library. Librarians use this library to describe a library containing a mixture of printed collections and digital collections. It is designed to combine technologies from different sources and explore integrated systems and services in the electronic and printed environment. To put it simply, hybrid libraries are a transitional stage of libraries that is not fully printable nor fully digital.

Tarumanagara University Library is one of the libraries that has implemented information technology in its management and automation system. Even if they used Information Technology in their designs, there are still users who complain because the digital facilities are inadequate and less sophisticated. The printed collections are still quite 
challenging to find. Apart from that, some visitors complained about the lack of private reading rooms and spaces for group work or innovation. Therefore, the authors are encouraged to design a modern Tarumanagara University Library with the purpose of easy and faster information access and service, as well as adjusting the character of the library design with the essence of the current generation, generation $\mathrm{Z}$.

\subsection{Methods}

This project is using Rosemary and W.Otie Kilmer method [10], which has three main stages: analysis, synthesis, and evaluation. In the analysis stage, the first step is to commit (redesigning the Tarumanagara University library), state (determine the problem of technology development and low visits as the main design problems), collect (the data is collected directly and indirectly, which then gets primary data: through documentation, interviews, online questionnaires and secondary data that is obtained through literature, and last is Analyze (analyzing the collected data programmatically). Then enter the synthesis stage, first is to ideate (defining a hybrid library in contemporary design as a design concept), choose (choosing the best design alternative), implement (realizing the design concept into shop drawings and perspective drawings). And the last step is evaluation. Review the design to determine whether the problems are solved or not, in this case, whether the hybrid library concept can solve the problem of low visits and technological advances for the digital generation.

\subsection{Paper Structure}

This paper starts with an abstract, showing a general summary of the paper. Section 1 is an introduction of the project, on the problems that led to the library's redesign, and why choose the hybrid concept. Subsection 1 explains the method used to redesign the library, using the three steps of Kilmer's technique. Section 2 is the results and discussion. Part 1 is about Tarumanagara University profiles, part 2 defines the hybrid concept, and part 3 describes the implementation of the hybrid idea on collaboration and self-circulation area. And the last, section 3 , concludes the paper.

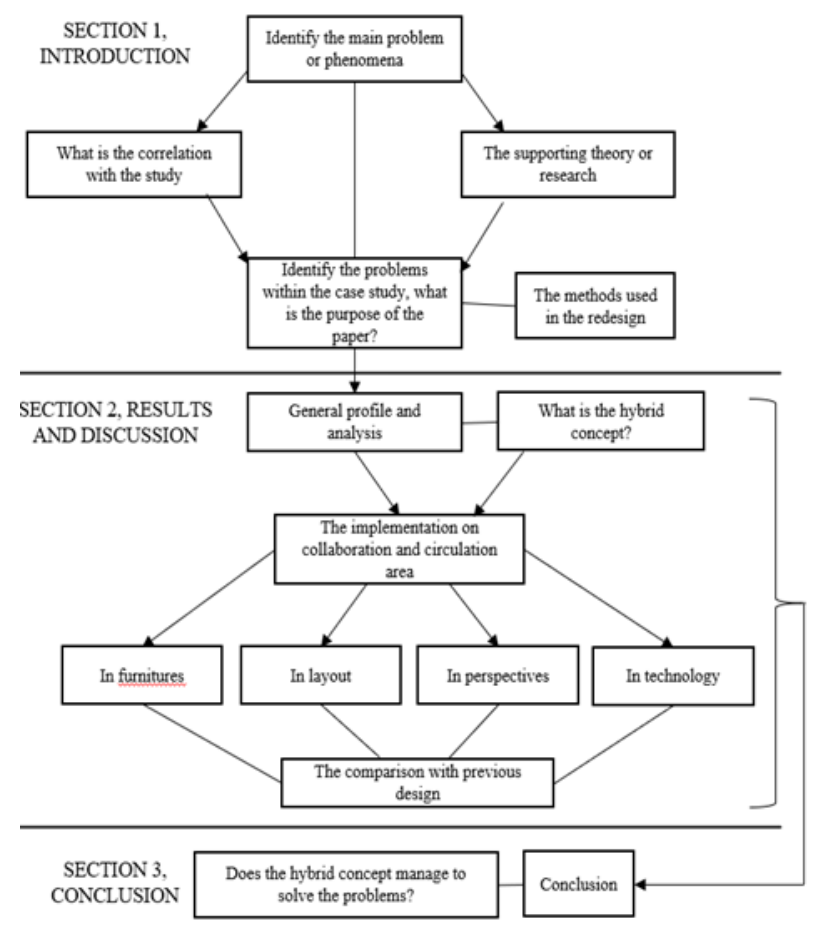

Figure 1 The schematic steps of the paper

\section{RESULTS AND DISCUSSION}

\subsection{Data Analysis}

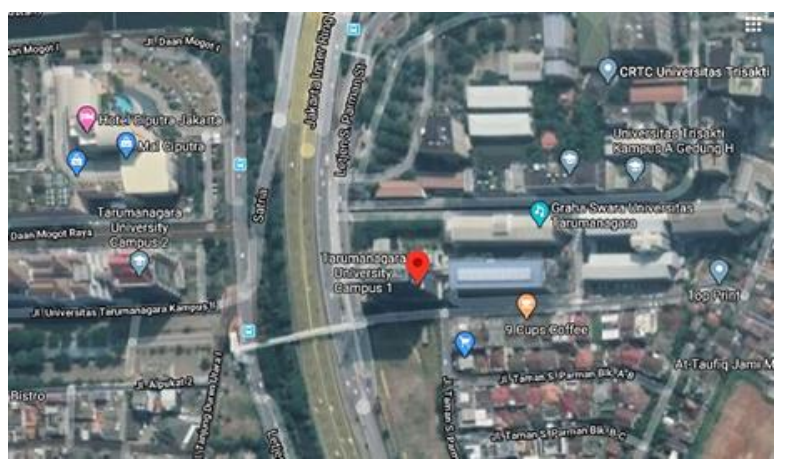

Figure 2 Tarumanagara University site plan

Tarumanagara University is located at Jl. Lt. Gen. S. Parman No.1, Grogol, West Jakarta, an urban area with heavy traffic. The library resides in the Main Building of Tarumanagara University Campus I. It consists of three floors as a college library and an exhibition room and a reading room. This library provides a collection room, reading room, meeting room, staff room, cinema room, OPAC, exhibition room, lounge, circulation/information area, and an exclusive staircase within the library. Broadly speaking, the Tarumanagara University library has implemented an automation system in its management, but not significantly. The visitors tend to be a college student 
aged 19-25 years, with the average number of visits per day is 200 visits within the university and 50 visits from outside the university.

\subsection{The Hybrid Concept}

'Hybrid Library' is the theme concept chosen in the redesign of this library. The Hybrid Library is applied as a step towards a fully digital library. Therefore, although it tends to use digitization, this library does not eliminate its conventionality but develops it slowly. Hybrid Libraries carry two services and two access to information: manual services by librarians and digital services by automatic machines. In contrast, data can be accessed through printed collections (which are placed on a bookshelf) and digital collections via electronic devices. The furniture is also equipped with technology and electrical sockets.

\subsection{The Implementation of Hybrid Library}

\subsubsection{Collaboration Area}

The collaboration Area is a well-organized area for group activities. Each section has different usefulness for users to carry out actions that require interaction with one another, like discussions, group study, briefing, and others.

\section{A. Facilities}

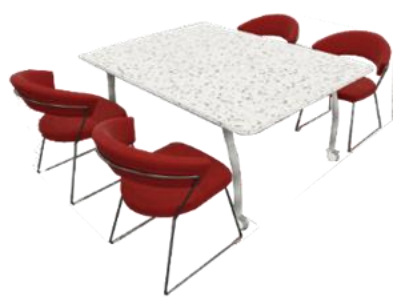

Figure 3 Modular moveable group table

It is a 4-seats group table with wheels to make it easier for users to move it according to the required capacity.

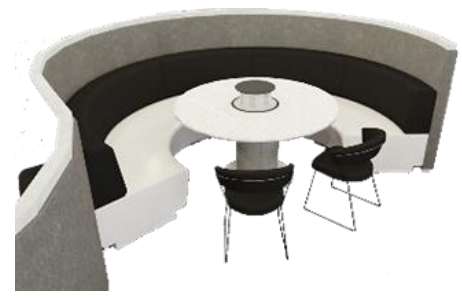

Figure 4 Modular round group table

It is a semi-open group table that has partitions attached to the furniture. This furniture can fit up to seven people.

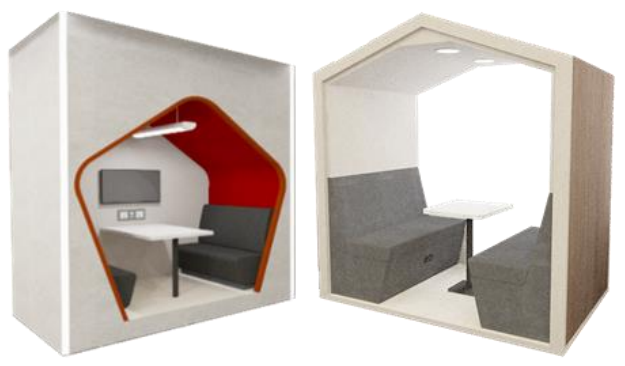

Figure 5 Meeting pods

A Meeting pod is a discussion/study area that is more private because it is enclosed with freestanding or built-in soundproof partitions, usually used for activities that require more privacy or quietness. This library has two types of meeting pods, one that is built-in on the wall (these pods are shaped resemble the Tarumanagara University logo) and one that is a moveable freestanding pod.

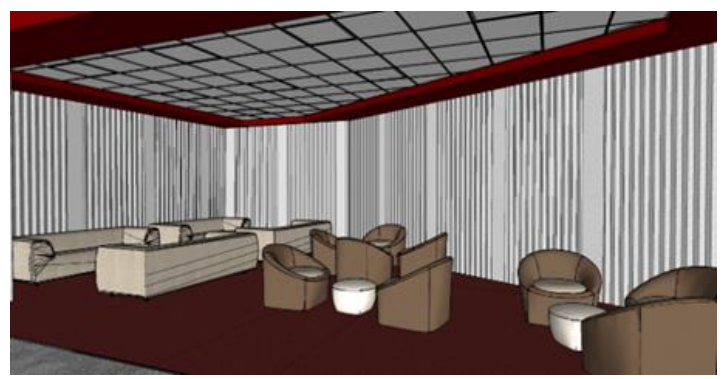

Figure 6 Relax Zone

It is an open discussion area that is more casual. This area provides a single sofa and double sofa with an ottoman, both as a table and seat.

B. Design implementation

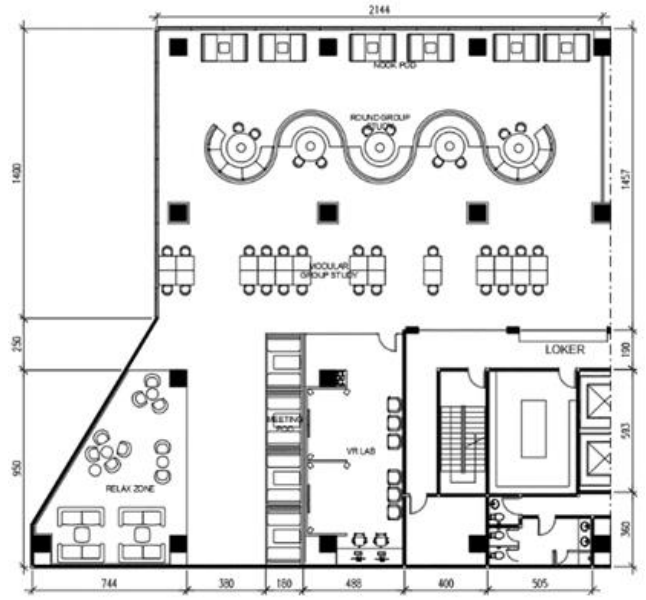

Figure 7 Collaboration Area Layout 

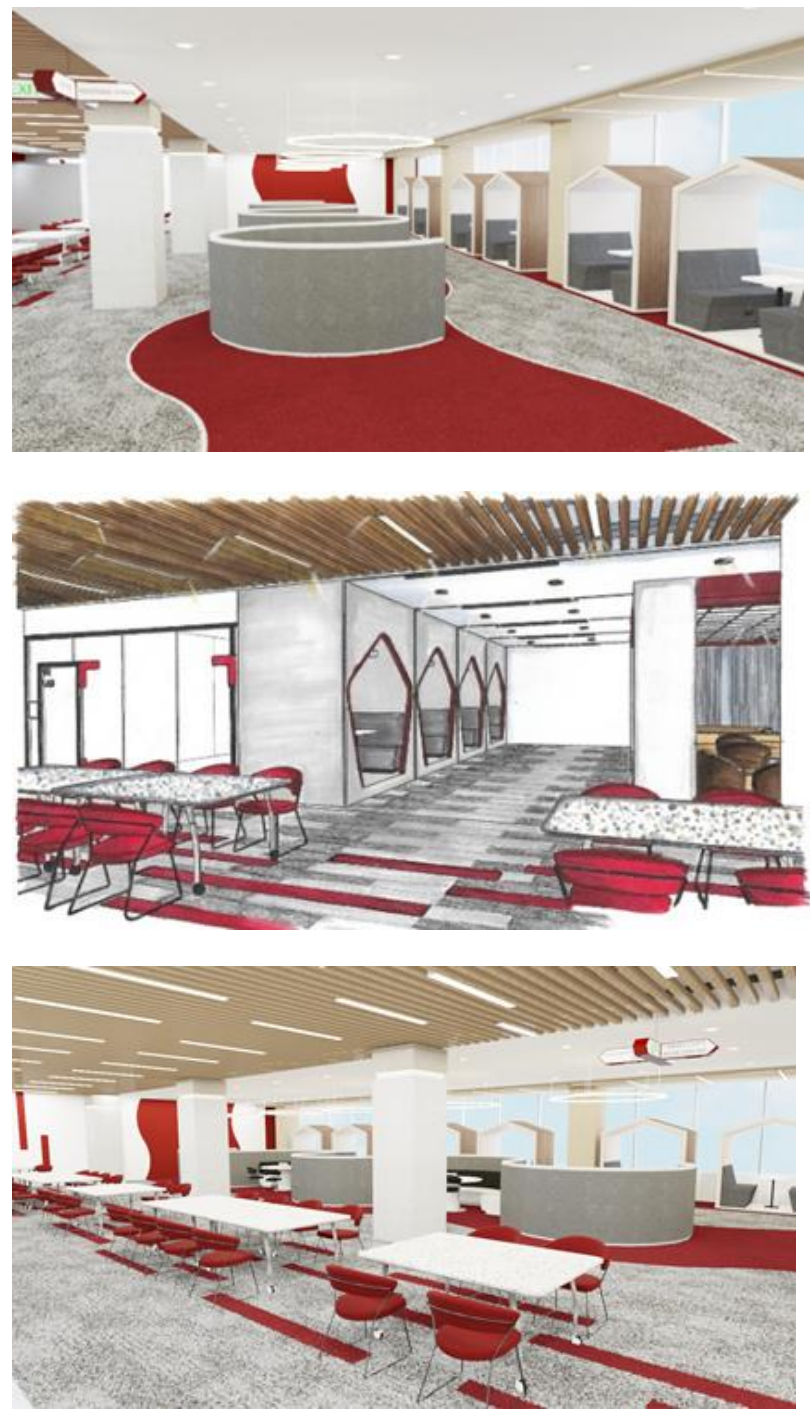

Figure 8 Collaboration perspectives

Collaboration Area is a multi-functional area, based on the user's characteristics who like to socialize and value privacy. The layout is open-plan. Each section is bounded by furniture partitions or material. The furniture is equipped with soundproof materials and technologies, such as LED TV and electrical sockets. There is also a Virtual Reality $\mathrm{Lab}$, a room for virtual educational learning space. This VR Lab has several facilities: VR cubicles, a control desk, VR tools, and interior construction standards for VR room, such as soundproofing, easy-to-open ceilings, and non-slip floors.

The contemporary style can be seen from the use of sustainable materials and clear-cut spatial boundaries. The furniture is simple, doesn't have many ornaments. It also uses neutral colors such as cream, mocha, dark gray, light gray, and white and features colors that reflect UNTAR characteristics, like black and red.

\subsubsection{Circulation Area}

A self-circulation area is a place for visitors to check-in and check-out independently, for activities like borrowing books, returning books, and access to the library catalog.

\section{A. Facilities}

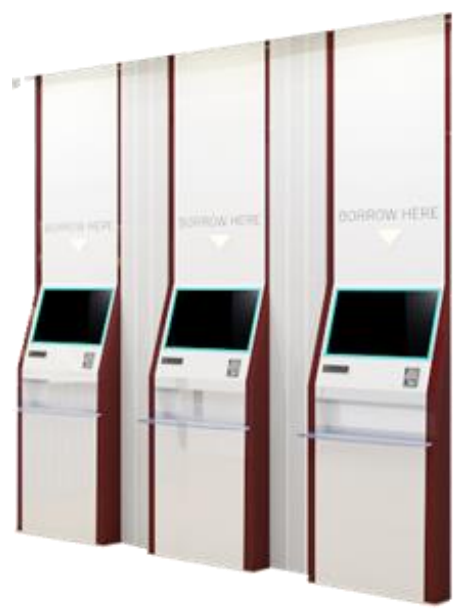

Figure 9 Self-borrow machines

It uses RFID technology, where the machine will scan the RFID tag in the collection and then register the borrowing. However, this technology only available for registered members. Therefore users must log in first. Finally, the machine will inform the deadline for the return with a receipt.

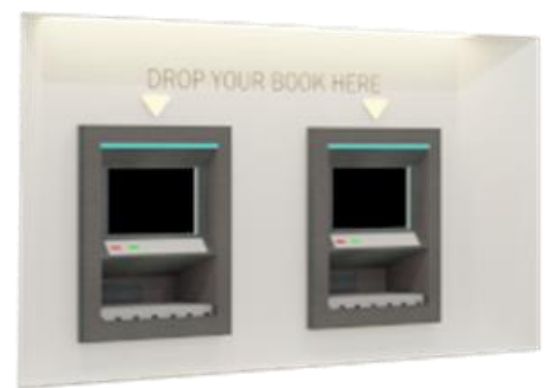

Figure 10 Self-return machines

This machine uses the same technology as the book-borrow machine, where the device will scan the RFID tag then register the returns made by users. The books that have been checked will then go through a sorting machine in the sorting Room to be categorized and returned to the collection area. 


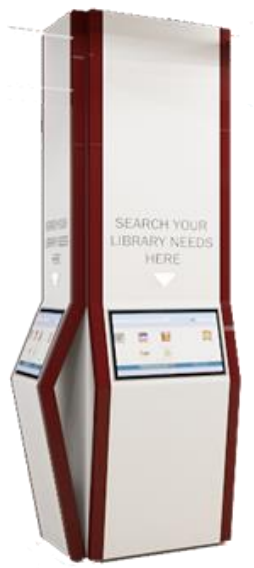

Figure 11 Standing OPAC

The OPAC is a touchscreen online catalog that provides information about the library collections. Users who want to find a particular collection can type the keyword, and then the machine will display the 3D Navigator to make it easier for the user to know the location.

\section{B. Design Implementation}

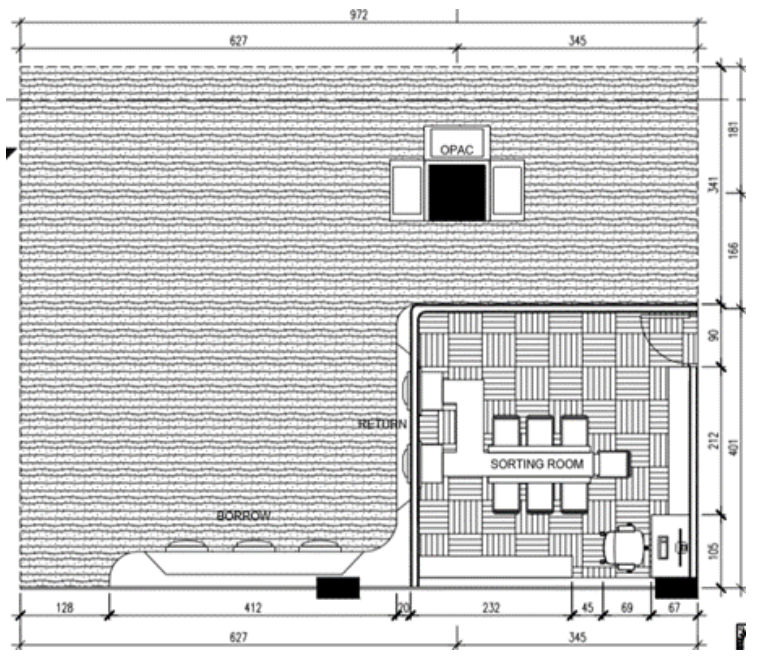

Figure 12 Self-circulation layout

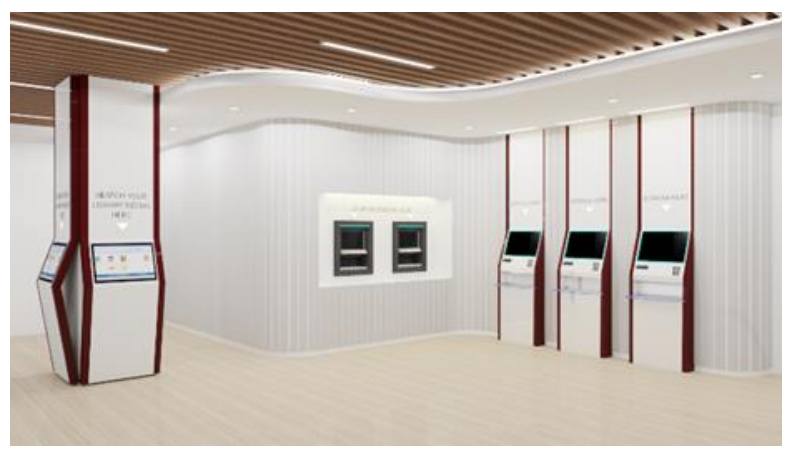

Figure 13 Self-circulation perspective
The Self-circulation area is divided into two areas, the open area (for users) and the closed area (for librarians), namely the sorting Room. The sorting Room is used to sorted recent returned books. This machine runs automatically with the librarian's supervision, and the returned books will be scanned by RFID technology then separated according to each category into a 'collection bin.' The book's condition will be checked first and then returned to their display collection.

This Room uses a modern contemporary style, with the use of simple interior elements, there is not much decoration. The ceiling uses a type of slat ceiling with a wood pattern, the walls use plain white panels, and the floor is a Linoleum Marmoleum white ash type. The colors are neutral (white, cream, mocha, and black) and use sustainable materials (linoleum, gypsum, and concrete). Meanwhile, the signage uses dyed acrylic with hidden LED.

Based on the results and discussion, a survey was created to determine the success of the hybrid concept application.

\section{Respondents Profile}
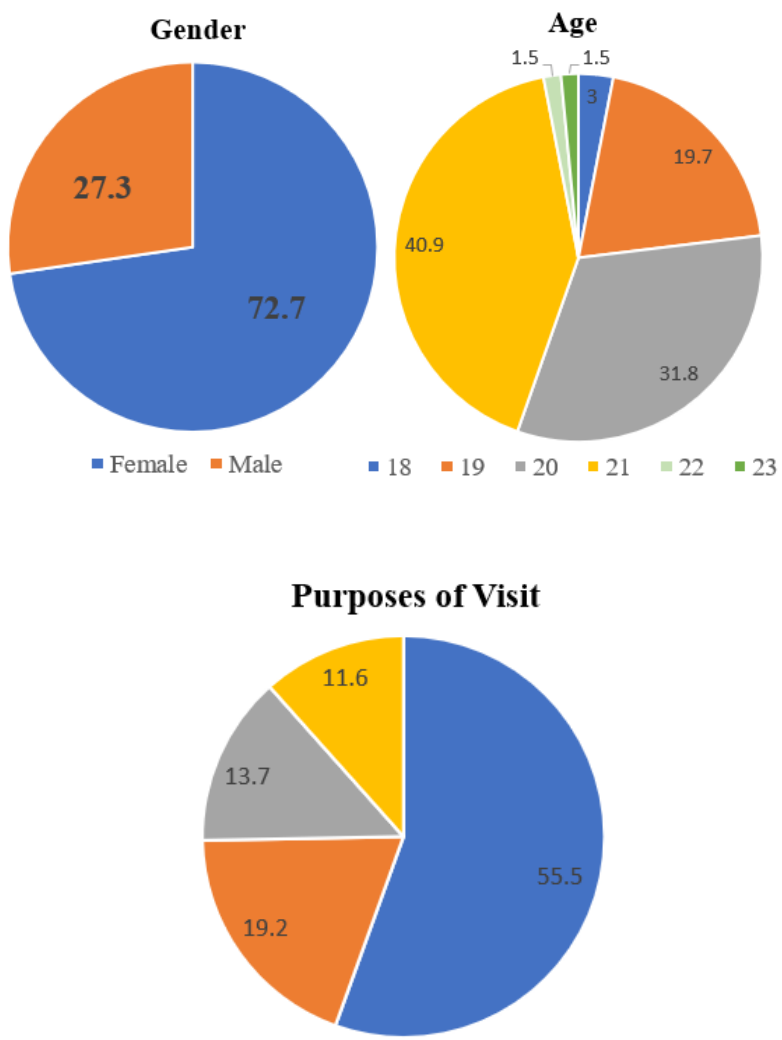

\section{- Doing Assignments aroup Activities \\ n Gain Knowledges $\quad$ Fill Out Spare Time}

Figure 14 Respondents profile charts 


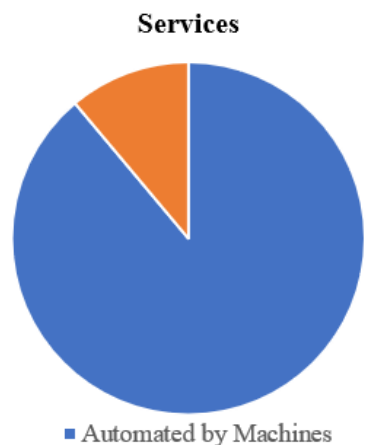

- Manual by Librarians
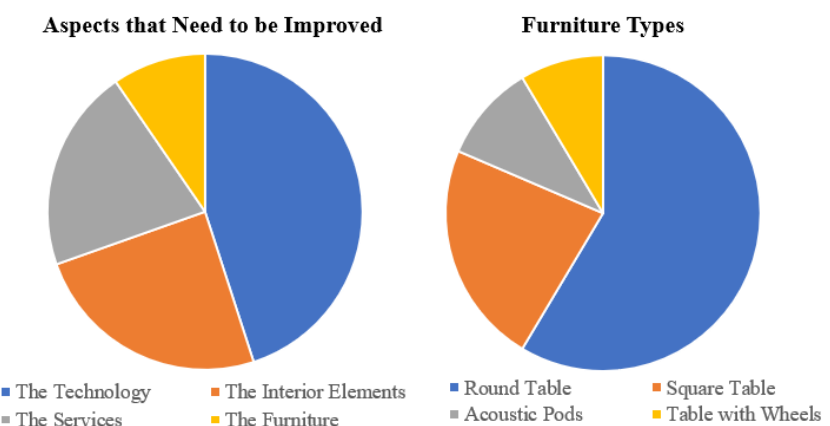

Layout and Circulation

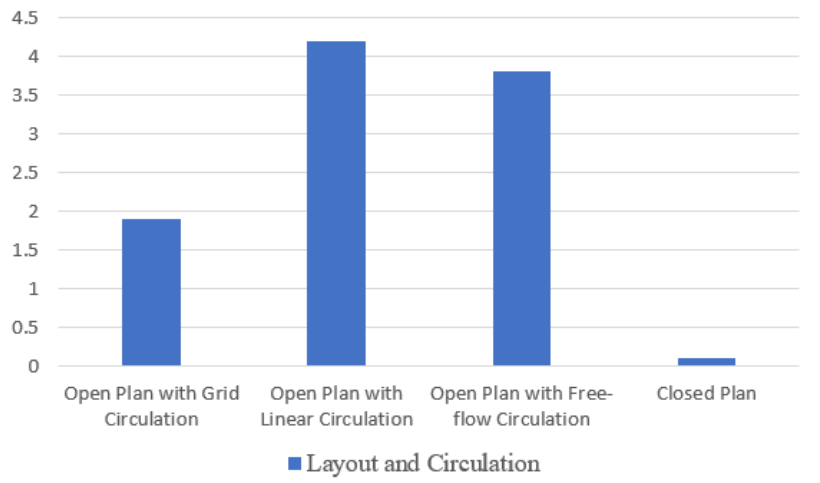

Interior Elements

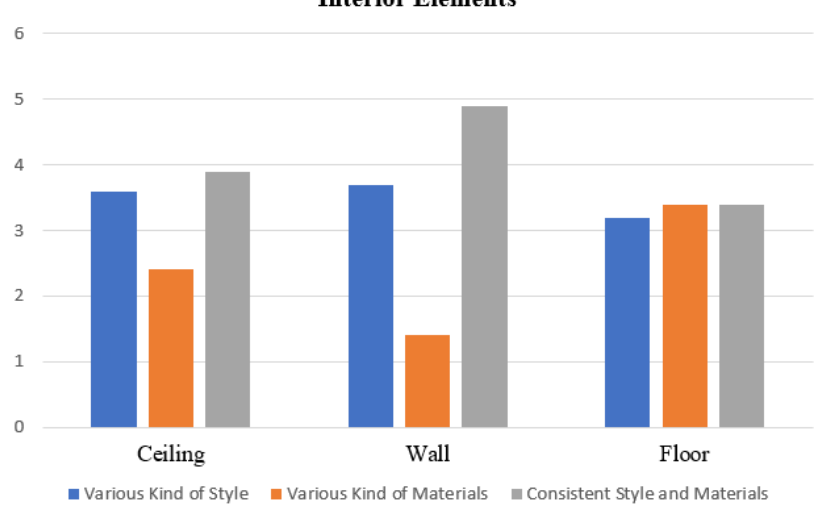

Figure 15 Respondents answers analysis chart
The respondents are between 18-23 years old (Gen Z), with a female majority. Most of them visit the library to work on assignments. They prefer automated services rather than manual services by librarians, which corresponds to the hybrid concept. According to the charts, they still find it difficult to search collections. That's why the hybrid concept tends to increase digital collections, which are more practical and easy to find. The forms of the furniture are more varied and multifunction. The majority voted that an open plan with linear circulation is better. The library uses more technology, more automated services, and more sophisticated devices, which are preferable according to respondents. Therefore, it can economize the time and space for users and librarians. In terms of aesthetics, more variations in shapes, sizes, and materials are applied so that the library looks more attractive and less tedious.

\section{CONCLUSIONS}

The hybrid library is the transition stage of conventional libraries to digital libraries, where libraries tend to use digital technology. The hybrid element in this library can be seen from the collections that provide digital and printed collections, from services that have digital services (RFID machines) and manual services by librarians, and from the interior, which combines the contemporary style and the formality of Tarumanagara University with the use of Interior elements as the space boundaries. Based on the respondent's charts, the hybrid concept can enhance the library, both in furniture, layout, technology, and interior elements. The hybrid concept makes a more advanced and modern design in tune with the generation. In conclusion, this hybrid library's plan can provide the Tarumanagara University library user's needs: generation Z, by prioritizing digital technology, collaboration spaces, and automation systems. The study of the hybrid library is comprehensive and has the potential to slowly develop until it reaches the stage of a fully digital library.

\section{REFERENCES}

[1] P. Leonard, Literature After Globalization: Textuality, Technology, and the Nation-State, United Kingdom: Bloomsbury Academic, 2013.

[2] N. Pareek and A. Gangrade, "Role of the Libraries as Information Resources in Globalization," International Journal of Librarianship and Administration, vol. 7, no. 1, pp. 13-23, 2016.

[3] S. Gaidhani, L. Arora and B. K. Sharma, "Understanding The Attitude of Generation Z Towards Workplace," International Journal of Management, 
Technology And Engineering, vol. IX, no. I, pp. 28042812, 2019.

[4] A. Dolot, "The Characteristics of Generation Z," $e$ mentor, pp. 44-50, 2018.

[5] T. A. Taufiq, Mengembangkan Karakter Sukses Anak Di Era Cyber, Yogyakarta: Ar-Ruzz Media, 2011.

[6] A. F. Marisman, "Mengenal Generasi Z," Kompasiana, 27 October 2016. [Online]. Available: https://www.kompasiana.com/firasz/581117bdcd9273e 62b3c887a/mengenal-generasi-z. [Accessed 30 December 2020].

[7] F. W. Lancaster, "Second Thoughts On The Paperless Society," Library Journal, vol. 124, pp. 48-50, 1999.

[8] A. Nurhayati, "Perkembangan Perpustakaan dalam Pemenuhan Kebutuhan," Jurnal Perpustakaan, vol. 9, no. 1, pp. 21-32, 2018.

[9] C. Oppenheim and D. Smithson, "What is the hybrid library?," Journal of Information Science, vol. 25, no. 2, pp. 97-112, 1999.

[10] R. Kilmer and W. O. Kilmer, Designing Interior 2nd Edition, New Jersey: John Wiley \& Sosn, Inc, 2014. 